\title{
DISPUTAS DE SENTIDO DE JUVENTUDE: \\ O QUE A MEDIDA PROVISÓRIA ENCERRA
}

QUARRELS ON THE MEANING OF YOUTH: WHAT THE INTERIM MEASURE ENDS

\author{
Raquel A. L. S. Venera \\ Docente da Univille \\ raquelsenavenera@gmail.com
}

Resumo: Este artigo é uma reflexão que nasceu no contexto da publicação da Medida Provisória n. ${ }^{\circ}$ 746, de 2016, transformada na Lei n. ${ }^{\circ}$ 13.415, de 2017, mas também, e sobretudo, com base em um conjunto de análises anteriores sobre sentidos de juventude em disputas no jogo de linguagem nas políticas curriculares para o ensino médio. As análises foram produzidas em uma rede de pesquisas com caminhos epistemológicos diferentes, porém com intenções e resultados muito próximos. Esta reflexão destaca especialmente uma dessas pesquisas, que, pelo caminho da análise do discurso $(\mathrm{AD})$ em diálogo com Orlandi (2011), analisou a política curricular Programa Ensino Médio Inovador (ProEMI), proposto pelo Ministério da Educação, e o ensino médio integral, desenvolvido pela Secretaria de Estado da Educação de Santa Catarina. Essas análises dão visibilidade aos sentidos de juventude em disputa, e esta reflexão entende a medida provisória como uma tentativa de encerrar a disputa em questão.

Palavras-chave: Políticas curriculares; Discursos; Juventude.

Abstract: This article is a reflection from the context of the publication of the Measure no. 746, from 2016, that became Bill no. 13,415, in 2017, but also, and mainly, based on the group of former analyses about youth meanings in disputes in the language game on the curriculum policies regarding high school. These analyses were made in a net of investigations, with different epistemological paths, with very close intentions and results. The present reflection highlights one of these analyses, which, through discourse analysis together with Orlandi (2011), analyzed the Programa Ensino Médio Inovador (ProEMI; Innovative High School Program). These analyses provide visibility to the youth meanings in disputes, and the present reflection understands the interim measure as an attempt to end the dispute.

Keywords: Curriculum policies; Discourses; Youth. 


\section{Introdução}

"Compare: saber e dizer - quantos metros de altura tem o monte Branco - como é usada a palavra 'jogo' - como soa um clarinete. Quem se admira de que se possa saber algo e não se possa dizer, pensa talvez num caso como o primeiro. Certamente não pensa em um caso como o terceiro."

(WITTGENSTEIN, 1999.p. 56).

O desafio em definir os sentidos das palavras torna-se muito mais intrigante diante da constatação de que as experiências sentidas escapam dos limites da própria linguagem. Desafio impossível. Dizer sobre o som de um clarinete é transformar em palavras um real auditivo, sentido e sem ancoragem concreta no jogo da linguagem. As palavras que rodeiam as significações de juventude desvelam um anseio pela definição de um fenômeno que aparentemente parece ser concreto, mas que se mostra furtivo e escapa, no jogo da linguagem, das definições que o tentam capturar.

Juventude já funcionou ao longo do século XX como sinônimo ou metáfora de vitalidade, liberdade, futuro da nação, rebeldia, sujeitos propulsores das revoluções, ruptura de tradições, entre outros. Em meio a tantos deslizamentos de enunciados, a definição cronológica parece fixar sentidos mais duradouros, no entanto também se mostra frágil diante de contextos diversos. A crítica literária Beatriz Sarlo (1997), ao analisar a contemporaneidade, fala de um "estilo jovem" e história os sentidos de juventude. Segundo a autora, em 1900 uma mulher imigrante com dois filhos aos 17 anos e casada com um homem dez anos mais velho não se considerava jovem. E seu marido já era um homem maduro. Os pobres passavam da infância ao mundo do trabalho e quem não se enquadrasse nessa rotina era interpretado como um jovem delinquente. Ela lembra a reforma universitária de Córdoba, em 1918, cujos revolucionários se declaravam jovens, assim como os revolucionários cubanos e os que marcharam pelas ruas de Paris em maio de 1968. Mas, em 1917, os líderes da Revolução Russa não se consideravam jovens. Relativizando com base na História, ela nos fala que o conceito de juventude é polissêmico, de acordo com o espaço e os tempos diversos (SARLO, 1997, p. 37).

Por esse caminho temporal, também Jon Savage (2009) historia o uso publicitário do termo teenager, datando o fenômeno de meados do século $\mathrm{XX}$, que definiu o jovem como um consumidor em potencial, além de criador e disseminador de novos consumos 
e formas de consumo. O teórico passeia em vários tempos e espaços mencionando ainda no século XIX alguns registros na Europa. Ele foca os sentidos de delinquência juvenil e o engajamento político desde a juventude hitlerista, o swing e zazous, os recrutas relutantes e heróis socialistas, as bandas de jazz e os consumidores potenciais até o triunfo do teenager.

Esses trabalhos que localizam os sentidos de juventude no tempo são importantíssimos para lembrar que as análises que naturalizam a condição do jovem ou fixam o sentido de juventude cronologicamente parecem não contemplar as especificidades da condição dos sujeitos jovens, e parece haver ainda mais a saber sobre os jovens na contemporaneidade do que as narrativas sobre seu passado. Investigar a juventude, saber sobre ela, defini-la parece ser um fenômeno social que acompanha a tendência latino-americana. Rosangela Barbiani (2007) alerta para o perfil demográfico da América Latina em sua dimensão expressivamente juvenil e vulnerável pelo empobrecimento estrutural. Ela destaca:

\begin{abstract}
Na sociedade globalizada econômica e culturalmente, entretanto, já não é possível ou suficiente fazer simples comparações de época. A centralidade da juventude nesse contexto é discutida (mais do que requerida) à luz da crítica às posições tradicionais e extremistas que ora situam os jovens como redenção da humanidade, ora como ameaça ou desvio à ordem social posta. (BARBIANI, 2007, p. 142).
\end{abstract}

Existem vários conceitos de juventude e adolescência, principalmente os norteados pela psicologia e sociologia, que nem sempre determinam uma cronologia, e outros relacionados às decisões de políticas públicas, considerando, sobretudo, o futuro adulto, a entrada no mercado de trabalho e/ou a idade biologicamente fértil. Para Corti e Souza (2004, p. 18),

[...] a modernidade também sedimentou uma definição de juventude e de adolescência largamente calcada nas classes altas e médias, transformando suas imagens em modelo privilegiado. Daí o estranhamento e a incompreensão das sociedades diante das novas juventudes, provenientes dos setores populares, que passam a ocupar as cidades com novas questões e problemas que já não dizem respeito ao modelo de juventude vigente. 
Neste texto, levamos em conta as formas de ver a adolescência e a juventude por meio de reflexões acerca da cultura - "[...] especialmente aquelas que nos remetem à dinâmica das lógicas temporais -, que se interessam, sobretudo, com a fabricação desses conceitos na contemporaneidade." (GABRIEL; LEITE; VENERA, 2012). No cotidiano, não é raro o tratamento dos dois conceitos como sinônimos. Isso fica evidente nas explicações do Dicionário Aurélio (FERREIRA, 1987). Considerando o dicionário como um instrumento da cultura, em que os discursos são difundidos, parece não haver diferença entre os dois conceitos. Lá (FERREIRA, 1987) aparece como sinônimo "a 'mocidade', 'idade moça' ou 'juventa', o que não explica o que seria especificamente a juventude, mas, ao conceituar a adolescência indica as idades de 12 a 20 anos, o que seria, também, sinônimo de uma 'idade moça'" (GABRIEL; LEITE; VENERA, 2012, p. 24). Para evitar que esses conceitos sejam apresentados de forma vaga ou mesmo como sinônimos, entendemos que os dois conceitos são distintos, embora sob alguns aspectos se convirjam.

A aposta é conceber um conceito de juventude/adolescência que tome o processo de significação/identificação de maneira ampliada. Assim, não se leva em consideração aqui a cronologia demarcada pelos órgãos ou pelos documentos oficiais. Sendo assim, explicita-se:

De acordo com a Organização das Nações Unidas (ONU) e a Organização Mundial da Saúde (OMS), compreende-se por jovens, no Brasil, as pessoas de 15 e 24 anos, e existe ainda a discussão para estender essa fase até os 30 anos. A definição dessa faixa de idade possui relação com a qualidade e expectativas de vida em um país, é uma categoria sociológica e política que implica na preparação dos indivíduos para o exercício da vida adulta, sua condição como idoso e a garantia de previdência social. (GABRIEL; LEITE; VENERA; 2012, p. 25).

Para as mesmas instituições, a adolescência é um processo biológico que vai dos 10 aos 19 anos, abrangendo a pré-adolescência dos 10 aos 14 anos e a adolescência dos 15 aos 19 anos. Como já citado, o Estatuto da Criança e do Adolescente (ECA) (Lei Federal n. ${ }^{\circ} 8.069 / 90$ ) (BRASIL, 1990) demarca a adolescência como a fase que vai dos 12 aos 18 anos incompletos, como período posterior à infância (GABRIEL; LEITE; VENERA, 2012). Desse modo, é fundamental ter a clareza de que a cronologia é norteadora das 
políticas e carrega uma noção de temporalidade de vida bem marcada. Ou seja, as políticas específicas para crianças, adolescentes, jovens sexualmente ativos, idosos aposentados e idosos trabalhadores possuem a faixa etária como parâmetro. Mas, ao significar os jovens, haja vista sentidos específicos - a idade é um deles -, os currículos evocam locais de sujeitos para esses jovens. Que locais são esses?

Essa inquietação foi perseguida pela pesquisa interinstitucional intitulada Abordagens discursivas de juventude no tempo presente: questões metodológicas nas análises de textos curriculares $^{1}$, que, em três instituições distintas e em diferentes abordagens discursivas, analisaram textos curriculares destinados a jovens. $\mathrm{O}$ recorte das reflexões deste artigo privilegia especialmente uma pesquisa que investigou os sentidos de juventude em políticas públicas e evidenciou alguns sentidos em disputa. $O$ que se põe em evidência nesta reflexão é que a Medida Provisória n. ${ }^{\circ}$ 746, de 2016 (BRASIL, 2016), que se transformou na Lei n. ${ }^{\circ} 13.415$ de 2017, escancara um jogo que não é novo. Materializa um momento do jogo político da linguagem em que os jogadores dão xeque-mate diante de um veredicto que se pretende final. Ou seja, o que vemos hoje como política para o ensino médio não nasceu agora, contudo está sendo engendrado nos sentidos de juventude e nas políticas anteriores. $\mathrm{O}$ que se tem de novo é a forma como as regras do jogo se impuseram.

Para construir a análise, este artigo está assim organizado: no primeiro momento, são apresentadas as análises do Programa Ensino Médio Inovador (ProEMI), proposto pelo Ministério da Educação (MEC) (BRASIL, 2009) e implementado pela Secretaria de Estado da Educação de Santa Catarina (SEESC) (SANTA CATARINA, 2011)2. No segundo momento, são traçadas algumas reflexões acerca da lei instituída com base na referida medida provisória. Nas reflexões finais, assumo um lugar político de analista do discurso e aponto algumas possibilidades de um jogo que recomeça ou pode continuar

\footnotetext{
${ }^{1}$ Pesquisa coordenada pela Professora Doutora Carmen Teresa Gabriel, da Universidade Federal do Rio de Janeiro (UFRJ), conta também com o núcleo da Universidade do Estado do Rio de Janeiro (Uerj), em parceria com a Professora Doutora Miriam Leite, da Uerj, aprovado no Edital Chamada Ministério da Ciência, Tecnologia e Inovação (MCTI)/Conselho Nacional de Desenvolvimento Científico e Tecnológico $(\mathrm{CNPq}) /$ Ministério da Educação (MEC)/Coordenação de Aperfeiçoamento de Pessoal de Nível Superior (Capes) n. ${ }^{\circ}$ 18/2012. As análises escolhidas neste artigo foram produzidas em uma pesquisa vinculada a essa grande proposta.

2 Essa pesquisa foi desenvolvida juntamente com a Professora Eliene de Jesus Figueiredo Solto Meyer, mestre em Educação pela Universidade da Região de Joinville (Univille), em Joinville (SC). Pesquisadora do Grupo de Pesquisa Políticas e Práticas Educativas.
} 
por desvios. É uma reflexão que convoca professores para a “desobediência” comprometida com a juventude.

\section{Os sentidos de juventude nos discursos das políticas públicas curriculares para o ensino médio}

Por políticas curriculares entendo aquelas que apontam, investem e acionam a criação de currículos. A política curricular pode ser considerada como o eixo para a produção de formas eficientes de instituição e constituição de uma realidade (VALLE; DALLABRIDA, 2006), definindo os papéis dos professores e alunos e as suas relações, realocando funções de autoridade e iniciativa e assim determinando os conhecimentos e as suas mais diversas formas de apropriação. Ou seja, constituindo os sentidos dos sujeitos envolvidos nos currículos. Valle e Dallabrida (2006, p. 185) citam: "A política curricular, transformada em currículo, realiza, por fim, um processo de inclusão de certos saberes e de certos indivíduos, tendo por consequência a exclusão de outros". No “território contestado" que se mostra o currículo, materializa-se a luta por sentidos, por disciplinas, conhecimentos, saberes e práticas que são incluídos ou excluídos, ditos ou silenciados.

Consideramos conhecimento e currículo campos culturais de disputa e interpretação, em que os diversificados grupos tentam estabelecer seus domínios. Com base nesse entendimento sobre as políticas curriculares, o discurso do ProEMI, proposto pelo MEC e implementado pela SEESC, foi analisado pelas ferramentas oferecidas pela análise do discurso $(A D)$ de corrente francesa. Segundo a analista do discurso Eni Orlandi (2011, p. 12), a $\mathrm{AD}$ pode ser tida como "um método para pensar a língua, as línguas, as linguagens, os sentidos, os sujeitos, o mundo”. Nessa mesma direção, Lima (2003, p. 77-78) afirma:

A escola francesa prioriza os procedimentos "analíticos" que desestruturam os textos: trata-se de fazer aparecer o discurso como plenitude enganosa, cuja análise deve revelar a "inconsistência" fundamental, relacionando-o ao trabalho de forças inconscientes. 
É importante salientar que, para a $\mathrm{AD}$, o contexto de produção dos discursos é o meio pelo qual se constroem os sentidos do texto. O que foi possível dizer? Que escolhas e sentidos foram evocados por meio de um contexto e expectativas?

Esta pesquisa levou em conta especialmente a proposta da $\mathrm{AD}$ como método de leitura tendo em vista a tríade sujeito, história e linguagem e seus efeitos interpretativos. Especialmente a presente análise considerou que os textos em estudo revelam o limiar em que o indivíduo se fez sujeito transformando um discurso em texto, em arranjos de unidades textuais, mesmo que simbólicas. Temos nesse recorte de análises textos que materializam os discursos em tensões, em disputa por sentidos políticos de educação, de juventude, de cidadania, de protagonismo, entre outros. São sentidos em disputa que acionam práticas políticas. Por isso, entendemos as políticas curriculares como um campo, "um território contestado", como já foi mencionado.

Nesse "território contestado", faz-se necessário definir o texto e o discurso. A empiria de análise é um texto, mas em sua articulação com a $\mathrm{AD}$ o tomaremos como unidade de análise, mesmo que simbólica, mas uma unidade com início, meio e fim que materializa os discursos. Para Guimarães (2007, p. 13), “o texto é atravessado por várias posições do sujeito, sendo, também, uma dispersão de discursos”. Mas o sujeito na posição de autor do texto procura criar, como regulação de sentidos de leitura, uma ilusão de unidade textual, ao mesmo tempo em que tenta garantir também ao leitor uma unidade de sujeito assumindo a função-autor. É importante ter claro, porém, que essas unidades são simbólicas e que um texto carrega um coletivo de dispersões discursivas, assim como são carregadas de contradições as formações discursivas às quais o sujeito se filia.

O que apresentamos como unidades de análise são textos. Como explica Orlandi (2011, p. 112):

Uma unidade feita de som, letras, sinais diacríticos, margens, notas, imagens, sequências, com uma extensão dada, com (imaginariamente) um começo, meio e fim, tendo um autor que se representa em sua origem, com sua unidade, lhe proporcionando coerência, não-contradição, conferindo-lhe progressão e finalidade. 
Contudo é importante ressaltar que o trabalho simbólico que o sujeito exerce transformando suas ideias em palavras transmuta o discurso em texto. Está nos textos a materialidade dos discursos. Isto é, temos por meio da análise possibilidades de reconhecer a relação entre "o mensurável com o imensurável, o empírico com o simbólico e o político" (ORLANDI, 2011, p. 113). Dizemos, portanto, que estamos analisando os discursos, porque o sujeito na condição de autor está sempre ancorado no discurso, na formação discursiva, em um sentido escolhido quando produz o texto.

Especialmente esta análise considerou que os textos revelam o limiar em que o indivíduo se fez sujeito transformando um discurso em texto, em arranjos de unidades textuais, mesmo que simbólicas. Temos no nosso recorte de análises textos que materializam os discursos em tensões, em disputas por sentidos políticos de educação, de juventude, de cidadania, de protagonismo, entre outros. São sentidos em disputa que acionam práticas políticas.

Com essas considerações feitas, é preciso perguntar quem são os autores desses textos. Quem transformou os discursos em textos? Quem confeccionou a ideia de unidade nessas textualidades? Em que lugar de sujeito estavam? A que formações discursivas estavam afiliadas? Procurar por um sujeito na posição de autor de um texto proveniente de uma autarquia nacional pressupõe entender que se trata de vários sujeitos autores que respondem a uma formação discursiva política, mas que em sua heterogeneidade acaba o mesmo texto por se transformar em uma pulverização de discursos. O local que esses sujeitos ocupam: no caso do texto ProEMI, o MEC, a Secretaria de Educação Básica, a Diretoria de Concepções e Orientações Curriculares para a Educação Básica, a Coordenação Geral de Ensino; e no caso do texto Novas perspectivas para o cotidiano escolar: ensino médio integral, do Estado de Santa Catarina, a SEESC, a Diretoria de Educação Básica e Profissional e a Gerência de Ensino Médio.

Existe uma diretoria ou gerência para regular os sentidos e as concepções de educação básica nacional. Esse fato nos diz que as concepções entre os estados estão dispersas. O currículo não é um “documento neutro”, ele é forjado em um jogo de discursos dissonantes, e, nesse jogo, as brechas abrem-se e os documentos construídos em uma correlação de forças deixam abertas lacunas para serem preenchidas de acordo com as disputas de cada local. 
No caso específico de Santa Catarina outro sujeito na condição de autor além da SEESC apareceu no texto. Como norteador do documento havia o texto Protótipos curriculares de ensino médio e ensino médio integrado: resumo executivo (UNESCO, 2011). Trata-se de um referencial que tem "objetivos relacionados com a preparação para o mundo do trabalho e a prática social como foco de orientação para a aprendizagem" (SANTA CATARINA, 2011, p. 8). Estes protótipos são compreendidos como referenciais "usados pela escola na definição do currículo do ensino médio ou para a elaboração do currículo (e do plano de curso) do ensino médio integrado com a educação profissional" (SANTA CATARINA, 2011, p. 9) e não são considerados currículos prontos.

Além dos sujeitos também é fundamental a análise do contexto de produção dos discursos. Estes se materializam em textos haja vista a formação discursiva no tempo. $\mathrm{O}$ desafio de superar o binarismo que tem marcado as políticas curriculares para o ensino médio no Brasil - o ensino propedêutico e o ensino profissionalizante - é uma das marcas do contexto atual das políticas para esse nível da educação básica, pelo qual nasceu o ProEMI.

No Governo Lula, a ideia de protagonismo juvenil apareceu com mais destaque e por consequência na definição de políticas públicas de juventude, entendendo-se como protagonismo juvenil nas políticas em concordância com Melo e Duarte (2011, p. 237) o "reconhecimento dos papéis de distintos atores na formulação, validação, implementação e avaliação de políticas públicas de juventude". Nesse sentido, ainda os autores afirmam que essa discussão se iniciou em 2003 e em 2005 começou o processo de institucionalização das políticas para juventude no Brasil.

Nesse processo, destacam-se a criação da Secretaria e do Conselho Nacional da Juventude (2005); do Programa Nacional de Inclusão de Jovens: Educação, Qualificação e Ação Comunitária (ProJovem) (2006); do Programa Universidade para Todos (ProUni) (2005); do Programa de Apoio a Planos de Reestruturação e Expansão das Universidades Federais (Reuni) (2007); os Pontos de Cultura e as Praças da Juventude, entre outros que, apesar de não serem exclusivos de juventude, atendem, mormente, os jovens brasileiros pertencentes às camadas populares, em situação de defasagem escolar, desemprego e vulnerabilidade social (MELO; DUARTE, 2011, p. 237). 
No Brasil, a partir do século XX, os debates políticos sobre juventude ganharam força e "passaram a enfatizar aspectos singulares da experiência social dessa geração, identificando suas vulnerabilidades, demandas e potencialidades" (NOVAES, 2007, p. 253). Atualmente o discurso difundido nas políticas de juventude parte da ideia de que "os jovens devem ser sujeitos de políticas públicas específicas e de caráter transversal, que se diferenciam daquelas focadas sobre as crianças ou sobre os adultos, em virtude das particularidades vividas nesse período da vida" (CORTI; SOUZA, 2004, p. 85). Somente em 2010, a Emenda Constitucional n. 65 acrescentou a palavra jovem entre os indivíduos cuidados pelo Estado. A dificuldade de compreender a condição de ser jovem leva a sociedade a olhar para os jovens essencialmente pelo que eles não são. Conforme Corti e Souza (2004, p. 23):

Quando dirigimos nosso olhar à juventude nos preocupando apenas com o que ela acarretará para a vida adulta, tendemos a prescrever uma série de comportamentos e atitudes que só assumem sentido num tempo futuro. É um erro ancorar os jovens nesta temporalidade projetada, que faz sentido apenas para os adultos que já tiveram oportunidades de construir suas próprias experiências de vida e extrair delas suas lições.

O ProEMI nasceu de uma sequência de programas da União que materializam em conjunto as políticas para a juventude brasileira. Ela está no bojo das políticas públicas para a juventude, e os sentidos desse contexto podem aparecer materializados nos discursos que serão analisados. O ProEMI faz parte das ações do Plano de Desenvolvimento da Educação (PDE) como estratégia do Governo Federal de reestruturar os currículos do ensino médio com propostas que serão introduzidas no currículo escolar, aumentando o tempo do aluno na escola e diversificando as práticas pedagógicas no ensino médio. O documento orientador do ProEMI assegura que o programa "pretende estabelecer mudanças significativas nas escolas públicas de ensino não profissionalizante no País, revertendo os dados negativos referente a esta etapa da educação básica” (BRASIL, 2009, p. 7).

No Estado de Santa Catarina o acolhimento a essa política se deu em acordo com as Orientações para Organização e Funcionamento das Unidades Escolares de Educação Básica e Profissional da Rede Pública Estadual - 2013³. Em convênio originário do Parecer

\footnotetext{
${ }^{3}$ Documento disponível nas gerências regionais de Educação (Gered).
} 
CNE/CP n. ${ }^{\circ} 11 / 2009^{4}$, realizado com o MEC, Santa Catarina aderiu ao programa em 2009 e iniciou o desenvolvimento das atividades em 18 escolas da rede pública estadual em 2010. Atendendo às novas Diretrizes Curriculares Nacionais do Ensino Médio (DCNEM) e ao Decreto n. ${ }^{\circ}$ 7.083, de 27 de janeiro de 2010, que traz em seu artigo 1. ${ }^{\circ}$, sobre o Programa Mais Educação, a finalidade de contribuir para a melhoria da aprendizagem por meio da ampliação do tempo de permanência de crianças, adolescentes e jovens matriculados em escola pública, mediante oferta de educação básica em tempo integral, a SEESC, a partir de 2012, viabilizou a ampliação e a consolidação do ensino médio inovador/integral em 95 escolas da rede pública estadual de ensino. Com o ensino médio integral, em Santa Catarina, desenvolveu-se o ensino médio inovador, que se encontra em duas modalidades: integral e semi-integral, o último apenas três vezes na semana.

O contexto de produção desses textos foi marcado pelas ações políticas governamentais na educação brasileira que sucederam aos mandatos de Fernando Henrique Cadoso e Luiz Inácio Lula da Silva. Esses mandatos foram marcadas por demandas que diziam sobre a urgência por mudanças - uma verdadeira reforma em todos os níveis da educação. Nessa reforma os projetos e programas voltados para o ensino médio se destacaram na educação básica no país. Para Lopes (2008, p. 189), “a reforma do ensino médio pode ser considerada uma reforma particular, com especificidades derivadas do interesse conferido a esse nível de ensino na atual conjuntura político-social”.

Diante das considerações feitas - acerca dos sujeitos autores e de alguns contextos da construção dessa política -, podemos inferir que os diversos sentidos de juventude podem estar em conflito e em disputa no interior de uma política de currículo destinada a essa faixa de idade. Posta em cena essa organização dos artefatos da presente análise, iniciaremos por evidenciar os sentidos de juventude capturados nessas políticas curriculares.

O sentido de emancipação parece pairar no discurso do documento orientador do ProEMI. O texto estrutura-se com base em uma lógica em que é apresentado o problema histórico de déficit do ensino médio e em seguida são apontados alguns caminhos possíveis para o enfrentamento e a superação dessa realidade. Nesse jogo do texto de "um antes", "uma possibilidade presente" e "um possível futuro" o sentido de emancipação se

\footnotetext{
${ }^{4}$ Trata da proposta de experiência curricular inovadora para o ensino médio.
} 
faz. Podemos pontuar o primeiro sentido de juventude nesse movimento: o jovem como um sujeito que precisa ser emancipado, introduzido no mundo adulto com habilidades e competências para participar dele. Para o documento, esse modelo deve articular o trabalho, a ciência e a cultura na perspectiva da emancipação humana. Trata-se de uma política de currículo que dê conta de produzir esse local de sujeito para os jovens - um local de sujeito emancipado. Ou seja, o jovem, estudante do ensino médio, ainda que tenha frequentado currículos inspiradores na cidadania durante toda a sua vida escolar, ainda é alguém que carece ser emancipado.

A ideia de cidadania perpassa a maioria dos documentos educacionais brasileiros da atualidade e possui um sentido diferenciado de outros tempos. Hoje a cidadania é meta orientadora da educação desde a educação infantil, e os documentos direcionados para o ensino médio dão pistas de que ao final da educação básica os jovens deverão ser aptos a exercerem a cidadania plena. Uma cidadania que é atingida depois da conclusão da educação básica. A diferenciação entre quem é e quem não é cidadão aponta para complexas disputas no interior das sociedades. Nesse sentido, Carvalho (2002, p. 9) afirma:

Uma cidadania plena, que combine liberdade, participação e igualdade para todos, é um ideal desenvolvido no Ocidente e talvez inatingível. Mas ele tem servido de parâmetro para o julgamento da qualidade da cidadania e em cada país e em cada momento histórico.

Já no texto Novas perspectivas para o cotidiano escolar: ensino médio integral, o jogo da linguagem aponta outros contornos. Ao apresentar os eixos norteadores para o ensino médio catarinense, o discurso do protagonismo jovem aparece como pano de fundo da vida cidadã:

Tendo como eixos norteadores a sustentabilidade e o empreendedorismo, e, como base metodológica, o protagonismo, o currículo se desprenderá do modelo de aulas totalmente livrescas e sem sentido, para aulas contextualizadas e práticas, nas quais o jovem, ativo e participativo, desenvolverá ações de inserção social, e constituirá o conhecimento de forma coletiva, com visão interdisciplinar, relacionando-a com sua vida, sua moradia, sua escola, seu bairro, sua cidade, seu planeta, permitindo, desta forma, colocar-se efetivamente como cidadão com direitos e deve- 
res, porém, com participação ativa como agente de transformação da sociedade onde vive, exercendo efetivamente sua cidadania (SANTA CATARINA, 2011, p. 4).

O caminho para a inovação seria aqui deixar as aulas e os livros e ir para a inserção social a partir da sustentabilidade e do empreendedorismo? Qual o sentido de "aulas totalmente livrescas"? Poderiam ser as aulas que demandam estudos teóricos? Esse sentido seria oposto ao sentido da participação na comunidade? Essas perguntas fazem parte da análise porque o texto não oferece uma compreensão dessas questões. Ele lança uma ideia e a deixa solta para o leitor emitir sentidos. Há que se questionar como esse documento tem entendido a cidadania. Se os jovens estiveram contemplados em currículos voltados para a formação de cidadãos desde a educação infantil, conforme objetiva-se especificamente na Proposta Curricular do Estado de Santa Catarina e, de forma mais geral, nos demais documentos educacionais, agora no ensino médio seria o momento em que a cidadania seria uma prática? O que a palavra "efetivamente" provoca? E como entender esse sentido diante de expressões como "participação ativa" ou "transformação da sociedade onde vive"? Nesse ponto percebemos um sentido de juventude política atrelada à "sustentabilidade" e ao "empreendedorismo", um sentido de jovem com um potencial empreendedor que precisa ser desenvolvido.

O texto de Santa Catarina propõe "um contexto de pesquisa e intervenção com atividades empreendedoras e socioambientais, que exigirão o protagonismo dos jovens na construção e no desenvolvimento de uma comunidade de aprendizagem" (SANTA CATARINA, 2011, p. 7). Dessa forma, o texto aponta para um paradoxo em que anteriormente os sentidos de livros aparecem quase como sinônimos de aulas "conservadoras" e sem muita contribuição, sendo aulas “contextualizadas e práticas” mais adequadas. Portanto, como estabelecer contexto de pesquisa para os jovens atribuindo o uso de livros a ensino sem sentido? O documento não dá pistas de que os jovens terão participação ativa nesse currículo, mas esta análise questiona os sentidos de protagonismo juvenil sugeridos em um contexto do "mercado de trabalho", de "empreendedorismo" e de "sustentabilidade”. Com essa análise verificamos que o sentido de juventude está funcionando como sujeito com potencialidades empreendedoras.

Podemos dizer que o documento do ProEMI aponta para um sentido de jovem que necessita ser emancipado, e na rede pública estadual de Santa Catarina isso compreende 
um sentido de jovem que precisa se preparar para ser um futuro empreendedor: "Tendo como eixos norteadores a sustentabilidade e o empreendedorismo, e como base metodológica, o protagonismo" (SANTA CATARINA, 2011, p. 4). Os sentidos de "emancipação" e "empreendedorismo" estão funcionando como sinônimos na preparação da vida cidadã? Ambos projetam o jovem para um futuro, um vir a ser adulto cidadão. $\mathrm{O}$ documento do ProEMI quando não deixa claro o sentido de emancipação ainda assim abrange em um dos seus itens a necessidade de trabalhar como assunto os aspectos do empreendedorismo e dessa forma acaba permitindo esse tipo de apropriação. Seria proposital? Estariam esses sentidos em disputa nessas políticas curriculares ou propositalmente ocupam um mesmo território semântico?

Esses sentidos evocam identidades, convocam os jovens a lugares na vida adulta. Isso é um currículo que reproduz ou cria desafios? Se o sentido de juventude é ser alguém que precisa ser emancipado, parece imprópria a lógica das competências. Essa lógica, segundo Valle e Dallabrida (2006), opõe-se ao movimento de emancipação em que imperam a competitividade e o individualismo. O currículo é entendido aqui como "um campo de luta em torno da significação de identidades" (SILVA, 2005, p. 134), no qual domínios são postos. Os currículos constroem identidades dos discursos que evocam, registram marcas que não são as vozes dos jovens. É esse o sentido de sujeito carente de ser emancipado? O currículo revela-se como produtor de identidade, como potencial promotor de desigualdades. Para Silva (2005), o currículo é poder, seu discurso inclui ou exclui. Dessa forma, o currículo "está baseado na cultura dominante: ele se expressa na linguagem dominante, ele é transmitido através do código cultural dominante" (SILVA, 2005, p. 35).

Um segundo sentido de juventude foi capturado nas análises das orientações didático-pedagógicas do documento do ProEMI e nas possibilidades de financiamentos para as adaptações da estrutura física das escolas. Esses textos ressaltam que, para a aprendizagem ser efetiva, atrativa para o jovem, é necessário que o professor "possua instrumentos didático-pedagógicos para a dinamização de suas aulas, com material de apoio às práticas e recursos tecnológicos compatíveis com as exigências do mundo moderno" (BRASIL, 2009, p. 19). Notamos que, embora "o material de apoio às práticas e recursos tecnológicos" esteja relacionado às exigências do mundo moderno, em todo o restante do texto esse sentido está diretamente associado também a uma visão do jovem como 
sujeito versátil, dinâmico, plugado, que precisa ser seduzido pela tecnologia. Um sujeito que necessita de um professor munido de recursos tecnológicos para conquistá-lo. Assim, o documento do MEC traz no item “Apoio às Práticas Docentes" que

a estruturação de ambientes virtuais em cada escola de ensino médio é fator relevante do Programa Ensino Médio Inovador, contribuindo para o apoio as práticas didáticas do professor. [...] A proposta de que cada escola possua sua página virtual. [...] Com o auxílio da Internet e outras ferramentas de mídia. Tais estruturas se mostram importantíssimas para a aprendizagem de jovens e adulto (BRASIL, 2009, p. 19).

Em sequência, o documento aponta entre os itens financiáveis a "aquisição de material permanente e equipamentos", assim como a "aquisição de tecnologias educacionais (guias de tecnologia do MEC)" (BRASIL, 2009, p. 19). O sentido de juventude ligada à mídia evoca outros que não estão claramente explícitos, mas que aparecem com a necessidade de equipar as escolas. A "geração" anterior -hoje os adultos: professores, gestores, administradores da escola -, não acompanhou a velocidade midiática nem tecnológica. A “geração" atual - os jovens - parece não caber de forma confortável, seduzida nesse lugar. A intensa familiaridade que os mais jovens desenvolvem com essas inovações tecnológicas pode desenvolver novas, inesperadas e até, ao menos para alguns, indesejadas práticas que questionam padrões estabelecidos de comportamento.

O que faz definir essa proposta como currículo para a juventude? O documento propõe que as escolas criem parceria com a Secretaria Nacional de Juventude com o objetivo de articular ações em conjunto com a juventude. Que ações? O texto não deixa isso claro.

O programa estimulará a realização de estágio e a concessão de auxílio ao desenvolvimento de projetos integradores de iniciação à ciência, atividades sociais, artísticas e culturais, bem como outras proposições de atividades educativas de interesse dos estudantes (BRASIL, 2009, p. 19).

A orientação segue afirmando que "espaço e recursos pedagógicos apropriados às dinâmicas de ensino constituem pressupostos condicionantes ao sucesso da aprendizagem” (BRASIL, 2009, p. 19). Esse sentido de juventude conectada às tecnologias e às novas formas de comunicação deixam pistas no jogo da linguagem de que tanto se exige 
da escola e dos professores a atualização constante a favor das demandas do mundo externo à escola, além de exigir formação integral dos jovens quanto respostas a uma demanda de sedução desse jovem que precisa não só ter acesso à escola em tempo integral, mas permanecer nela.

No item "Apoio a projetos de pesquisa e estudos relativos ao ensino médio e juventude", o documento orienta:

A produção de conhecimentos relativos ao ensino médio e dos sujeitos jovens que frequentam ou deveriam frequentar esta etapa da educação básica subsidia a gestão dos sistemas de ensino e qualifica a prática docente no desenvolvimento de um projeto de inovação curricular nas escolas (BRASIL, 2009, p. 20, grifos nossos).

O documento escancara a carência de conhecimento sobre o entendimento da concepção de juventude no contexto das multiplicidades dos diversos grupos de juventudes recebidos pelas escolas. Conhecer quem são os jovens estudantes do ensino médio parece ser um desafio anunciado pelo ProEMI. O mesmo discurso que anuncia a necessidade de pesquisa sobre os jovens e o ensino médio faz emergir o terceiro sentido de juventude - sujeitos que não se conseguem significar, interpretar totalmente, que são uma incógnita e por isso se precisa pesquisá-los. Conhecer sobre o jovem para saber como melhor educá-lo, como seduzi-lo, para incluí-lo no mundo do trabalho e na vida social útil.

Como se os jovens fossem metaforicamente "monstros" que precisam ser decodificados. Jeffrey Jerome Cohen, um dos autores da Teoria dos Monstros, explica que o "monstro nasce nessas encruzilhadas metafóricas, como corporificação de um certo momento cultural - uma época, de um sentimento e de um lugar. [...] O corpo monstruoso é pura cultura” (COHEN, 2000, p. 27). Rosangela Soares (2000), estudiosa da adolescência como produção discursiva, afirma que a Teoria dos Monstros permite conhecermos as culturas por meio dos monstros que elas geram. E o terceiro sentido de juventude capturado no documento do ProEMI não seria outro jeito de assumir a existência de um monstro que não se deixa capturar? Um “outro" que funciona como um espelho voltado para o "dentro" de nós e que, por isso, tanto incomoda. Fabricado na nossa cultura, não conseguimos defini-lo completamente. Os discursos, tanto o biológico, que disseca o monstro até chegar aos seus hormônios, quanto o psicológico, que lhe disseca a psique, 
não o apreendem totalmente. Algo sempre escapa, como um vampiro que sempre retorna com outra roupagem e se recusa a morrer.

A juventude é a materialidade da diferença feita de carne, é a incorporação do fora, do além, daquilo que não conseguimos nomear totalmente e sempre nos escapa. Não é a criança, não é o adulto, tampouco é o jovem no sentido cronológico do termo. É uma ameaça à estabilidade das identidades sociais e culturais e, por isso, um monstro. Soares (2000, p. 157) fala sobre essa instabilidade da seguinte forma:

O que é atribuído ao adolescente - instabilidade, incerteza, mobilidade e transitoriedade - parece ter se deslocado para além dessa "fase de transição", a fim de assumir conotações da cultura de amplo significado. As identidades sociais instáveis, fragmentadas em oposição à fixidez, têm nos aproximado cada vez mais dos monstros. Não será esse excesso de proximidade que constitui o horror e o fascínio que sentimos por esses corpos monstruosos?

Pelo fato de não ocupar um lugar fixo e de borrar as identidades, os jovens não são vistos nem como crianças nem como adultos. Um sujeito da linguagem que por vezes não é tão convencionalmente assujeitado, por isso facilmente naturalizado pela medicina hebiátrica e pela psicologia, e, dessa forma, tornam-se protegidas as identidades estáveis ao seu entorno. Esse sentido de juventude aparece no documento do ProEMI de maneira sutil, mas evidencia a preocupação estatal de entender mais essa incógnita, esse sujeito que escapa no exato momento em que é interpretado e no próximo momento já não é mais aquela certeza.

Supõe-se que os sentidos de juventude que são destacados em uma política pública são aqueles que disputam a hegemonia. Durante o processo de análise, apontamos sentidos de juventude no jogo de linguagem do documento orientador do ProEMI, do MEC, considerando o jovem como alguém que precisa ser emancipado, conectado às "novas tecnologias" ou que necessita ser capturado pelo tecnológico e ainda um sujeito a ser interpretado, uma incógnita a ser desvelada. O documento Novas perspectivas para o cotidiano escolar: ensino médio integral, da SEESC, apresenta em seu jogo de linguagem um sentido de juventude atrelado ao sentido de jovem com potencial empreendedor a ser desenvolvido. 
Em ambas as políticas de currículo, o sentido de juventude como etapa de transição da vida pareceu bastante recorrente, uma vez que a natureza do discurso curricular prevê um lugar identitário ou evoca o sujeito a um lugar no mundo ao final do percurso. Quando Wittgenstein (1999) sugeriu o jogo entre "saber e dizer" na epígrafe deste artigo, entre responder à altura do Monte Branco e ao som do clarinete, talvez ainda seja mais possível medir o Monte Branco. Ao perseguir os sentidos de juventude nas políticas curriculares, talvez seja mais fácil e possível considerar a cronologia que marca o tempo de transição entre a infância e a fase adulta. Parece que esse sentido reforça a responsabilidade de construção de um futuro adulto mais ou menos estável socialmente - seja por um tipo de emancipação, seja por um investimento no empreendedorismo e na sustentabilidade.

Há que se atribuir sentidos de futuro, pelo fato de não ocupar socialmente um lugar de estabilidade e borrar as identidades mais ou menos fixas propostas pelos adultos. Esses sujeitos que não são mais vistos como criança e ainda não são tidos como adultos ocupam lugares de sujeitos da linguagem às vezes não tão convencionalmente "assujeitados", por isso facilmente naturalizados como "adolescentes". E, dessa forma, tornam-se protegidas as identidades estáveis ao seu entorno, mas ainda assim seus rolezinhos, seus estilos musicais, seus pixos e grafites nas paredes das cidades, suas estéticas de vida provocam instabilidades sociais e evocam aos adultos a necessidade urgente de pesquisa e decodificação desse fenômeno. Esse sentido de "incógnita" aparece no documento do ProEMI de forma sutil, mas evidencia a preocupação estatal de entender mais sobre a multiplicidade desse público - sujeitos que escapam no exato momento em que são interpretados e no próximo momento já não são mais exatamente aquela certeza da pesquisa anterior.

Cabe dizer que procuramos mostrar, via análise, que essas políticas de currículo desvelam sentidos de juventude que não estão explícitos, mas que norteiam as políticas e evocam lugares de sujeitos tanto para professores quanto para os próprios jovens. Jovens anunciados como sujeitos que precisam ser emancipados e inseridos no mundo adulto, capturados pela tecnologia, concebidos como potenciais empreendedores. Alguém que não se deixa capturar. 


\section{0 que a medida provisória quer encerrar}

Quando se diz que as políticas de currículo são "territórios contestados”, diz-se sobre as áreas do conhecimento que se tensionam em disputas de conteúdo, de níveis de importância e destaque do que será ensinado, diz-se também acerca dos sentidos sociais de sujeito político: quem são os estudantes que o currículo recebe, e também quem serão os egressos desse currículo e que identidade social se pretende construir durante o tempo nesse percurso planejado. Além disso, diz-se especialmente sobre a expectativa social que se impõe ao currículo, sobre quem deve ser o egresso da educação básica. Deverá o jovem saber sobre os conhecimentos eruditos acumulados pela nossa civilização? Ou deverá ele dominar ofícios que garantam o primeiro emprego? Ou, ainda, ter conhecimentos suficientes para continuar seus estudos na universidade? Quem deverá ser esse sujeito, não mais criança e quase adulto que dividirá o mundo cidadão com todos os demais? Deverá a escola se importar com uma educação moral? Religiosa? Laica? Ética? Esse sujeito deverá ser questionador? Empreendedor? Que sentidos de sociedade ele deve defender? Um sentido inclusivo, com lugares iguais a todos? Deverá o jovem pensar em uma sociedade com lugares iguais para os negros, as mulheres, as prostitutas, os trans, os gays, as lésbicas, os brancos, os homens? Um sentido excludente mantendo a histórica cultura machista, branca de homens bem posicionados economicamente? São muitas as contestações implicadas em uma política de currículo. Essas tensões formam uma grande rede. O currículo, em um Estado democrático, acontece nessa rede em movimento, ora tensionando em um determinado sentido, ora tensionando em outro em um jogo político de linguagem e luta por um sentido mais ou menos hegemônico, sempre provisório.

Principalmente, no contexto atual das políticas de currículo para o ensino médio, as disputas explicitam alguns pontos de tensão específicos que merecem atenção. Desde que o Projeto de Lei n. ${ }^{\circ}$ 6.840, de 2013, propôs discutir as mudanças da Lei de Diretrizes e Bases (LDB) n. ${ }^{\circ}$ 9.394/96, é sabido que os grupos empresariais e as grandes corporações educacionais tensionam para garantir uma educação técnica que responda às demandas do mundo corporativo. Não é necessária uma pesquisa sistemática na mídia para lembrar quem são os representantes desses grupos, como o Instituto Ayrton Senna, a Fundação Roberto Marinho e até representantes da própria Federação das Indústrias do Estado de São Paulo (Fiesp), que, de um lado, exigem mais disciplinas e formatos técnicos no ensino em nome de uma flexibilização e liberdade de escolha dos estudantes e, do 
outro, educadores, pesquisadores que em contrapartida apontam para a formação integral do estudante, com preocupações humana e social.

O ProEMI, lançado em 2010, era uma possibilidade de os estados e o Distrito Federal produzirem suas experiências curriculares e de forma sistemática as apresentarem em fóruns e debates nacionais e, então, após um grande debate nacional, ouvindo também os próprios estudantes, pais e professores, construir uma reforma do ensino médio consensuada. Embora a palavra consensuada talvez não seja a mais adequada, havia uma rede de poderes fazendo tensões no cenário político democrático. Como vimos nas análises desses programas, tanto no ProEMI quanto na experiência do Estado de Santa Catarina a disputa entre os sentidos de juventude direciona um lugar de sujeito para os jovens. O sentido cronológico vê-os como sujeitos em transição, e o sentido de carência de emancipação, como passivos à sedução pelas tecnologias enquanto uma incógnita social, evocando outro sentido que dá lugares de adequação e estabilidade para a vida adulta. Os vazios de sentidos deixam brechas no jogo da linguagem, a emancipação funcionando como sinônimo de empreendedorismo, por exemplo. Essa análise diz-nos que o jogo estava sendo jogado em um tabuleiro democrático e os discursos do mercado, da formação técnica para o trabalho, das respostas ao mundo corporativo estavam em vantagem.

Ainda assim, especialmente com o fenômeno de ampliação da rede federal com as inaugurações dos institutos federais pelo interior do Brasil, os discursos humanistas e de formação integral do estudante ecoavam de alguma maneira. Porém uma medida provisória é um gesto político que encerra o debate e apresenta um xeque-mate que muda as regras do jogo. Um golpe no jogo político da linguagem. É o momento em que se pretende parar o jogo, fixando o sentido que convém para os jogadores vencedores.

O documento estabelece:

Art. 36. O currículo do ensino médio será composto pela Base Nacional Comum Curricular e por itinerários formativos, que deverão ser organizados por meio da oferta de diferentes arranjos curriculares, conforme a relevância para o contexto local e a possibilidade dos sistemas de ensino, a saber:

I - linguagens e suas tecnologias;

II - matemática e suas tecnologias;

III - ciências da natureza e suas tecnologias;

IV - ciências humanas e sociais aplicadas;

V - formação técnica e profissional (BRASIL, 2017 grifos nossos). 
Logo, ele define que o ensino médio deve focar em uma aplicabilidade técnica, e a relevância local evidentemente será a paráfrase do atendimento da força produtiva local. Além dessa escolha, ainda está prevista "a inclusão de vivências práticas de trabalho no setor produtivo ou em ambientes de simulação, estabelecendo parcerias e fazendo uso, quando aplicável, de instrumentos estabelecidos pela legislação sobre aprendizagem profissional" (BRASIL, 2017), o que, em outras palavras, legaliza a "escola de fábrica" a receber menores de idade sob a justificativa de vivências práticas no setor produtivo. Ainda, o professor com notório saber poderá ser o próprio representante da empresa ou indústria local.

Por outro lado, a exclusão de conteúdos das ciências humanas que não possuem explicitamente caráter prático nem aplicável tecnicamente, como a História, por exemplo, revela a limitação da proposta ao atendimento do setor corporativo e sem nenhuma perspectiva de formação integral do estudante. Esse documento escancara que os sentidos de juventude como uma fase cronológica da vida e anterior à emancipação/ao empreendedorismo evocam os sujeitos para uma vida adulta útil, aplicada às demandas técnicas locais. As análises do ProEMI mostram que esses sentidos não são novos e venciam o jogo político nesse "território contestado", mas uma lei aprovada com uma medida provisória quer encerrar a própria disputa democrática.

\section{Reflexões provisórias}

A medida provisória intenciona parar o jogo político da construção de um currículo. Em grande medida, com a aprovação e implementação em forma de lei, esse fato é consumado. Acabaram os debates, os fóruns, os estudos, mas o território de currículo está aberto a contestação. A luta continua em outras instâncias, com outras armas em outros posicionamentos dos sujeitos. Essas reflexões anunciam a urgência de uma análise mais aprofundada tanto da medida provisória quanto da lei que muda os dispositivos de vários documentos jurídicos, incluindo a Consolidação das Leis do Trabalho (CLT).

A luta por sentidos para juventude enquanto acontecimento do presente é urgente: nem como a criança - que passou, que necessitava de tutela maior -, nem como o adulto - que ainda não é, com todas as responsabilidades de um cidadão -, muito menos apenas 
como um momento preparatório para a vida adulta, para se contaminar com os sentidos carpe diem das juventudes. Essa reflexão é um grito em defesa dos sentidos de juventude como potência, como sujeito que cria, que participa, que está aqui e agora com desejos reais. É uma reflexão que convoca professores para a "desobediência” comprometida com a juventude. E nesse local em que essa reflexão termina, contaminada pelo seu contexto de produção, caberia também uma fala de Wittgenstein (1999, p. 41): "Lá onde nossa linguagem autoriza a presumir um corpo, e não existe corpo algum, lá desejaríamos dizer, existe um espírito" que nos coloca perante a inquietação de pensar os sujeitos nos jogos de linguagem, sem nenhuma base ou segurança essencializadora que os garanta previamente um conceito, uma definição, uma identidade. Lá, onde os discursos fazem sentido, os jogos de linguagem são jogados, as articulações políticas são alçadas, os seres humanos são nominados e lá autorizamos “a presumir um corpo", em que as subjetividades se processam desautomatizadas de essências.

\section{Referências}

BARBIANI, Rosangela. Mapeando o discurso teórico latino-americano sobre juventude(s): a unidade na diversidade. Textos \& Contextos, Porto Alegre, v. 6, n. 1, jan./jun. 2007.

BRASIL. Lei n.o 8.069, de 13 de julho de 1990. Dispõe sobre o Estatuto da Criança e do Adolescente. 1990.

BRASIL. Lei n.o 9.394, de 20 de dezembro de 1996. Estabelece as diretrizes e bases da educação nacional. 1996.

BRASIL. Decreto n.o 7.083, de 27 de janeiro de 2010. Dispõe sobre o Programa Mais Educação. 2010.

. Ministério da Educação. Secretaria de Educação Básica. Programa Ensino Médio Inovador: Documento Orientador. Brasília: Ministério da Educação, 2009.

. Medida Provisória n. ${ }^{\circ}$ 746, de 22 de setembro de 2016. Institui a Política de Fomento à Implementação de Escolas de Ensino Médio em Tempo Integral, altera a Lei n. ${ }^{0} 9.394$, de 20 de dezembro de 1996, que estabelece as diretrizes e bases da educação nacional, e a Lei n. ${ }^{\circ}$ 11.494, de 20 de junho 2007, que regulamenta o Fundo de Manutenção e Desenvolvimento da Educação Básica e de Valorização dos Profissionais da Educação, e dá outras providências. 2016.

. Lei n. ${ }^{\circ} 13.415$, de 16 de fevereiro de 2017. Altera as Leis n. 9.394 , de 20 de dezembro de 1996, que estabelece as diretrizes e bases da educação nacional, e n. ${ }^{\circ} 11.494$, de 20 de junho de 2007, que regulamenta o Fundo de Manutenção e Desenvolvimento da Educação Básica e de Valorização dos Profissionais da Educação, a Consolidação das Leis do Trabalho 
- CLT, aprovada pelo Decreto-Lei n. ${ }^{\circ} 5.452$, de $1 .^{\circ}$ de maio de 1943, e o Decreto-Lei n. ${ }^{\circ}$ 236, de 28 de fevereiro de 1967; revoga a Lei n. ${ }^{0} 11.161$, de 5 de agosto de 2005; e institui a Política de Fomento à Implementação de Escolas de Ensino Médio em Tempo Integral. 2017.

CARVALHO, José Murilo de. Cidadania no Brasil: o longo caminho. 3. ed. Rio de Janeiro: Civilização Brasileira, 2002.

COHEN, Jeffrey Jerome. A cultura dos monstros: sete teses. In: SILVA, Tomaz Tadeu da (Org.). Pedagogia dos monstros: os prazeres e os perigos da confusão de fronteiras. Belo Horizonte: Autêntica, 2000. p.23-60.

CORTI, Ana Paula; SOUZA, Raquel. Diálogos com o mundo juvenil: subsídios para educadores. São Paulo: Ação Educativa, 2004.

FERREIRA, Aurélio Buarque de Holanda. Dicionário da Língua Portuguesa. Rio de Janeiro: Nova Fronteira, 1987.

GABRIEL, Carmen T.; LEITE, Miriam S.; VENERA, Raquel A. S. Abordagens discursivas de juventude no tempo presente: questões metodológicas nas análises de textos curriculares. Projeto de Pesquisa. Rio de Janeiro; Joinville, 2012.

GUIMARÃES, Eduardo. Texto e argumentação: um estudo de conjunções do português. 4 . ed. Campinas: Pontes, 2007.

LIMA, Maria E. A. T. Análise do discurso e/ou análise de conteúdo. Psicologia em Revista, Belo Horizonte, v. 9, n. 13, p. 76-88, jun. 2003.

LOPES, Alice C. A articulação entre conteúdos e competências em políticas de currículo para o ensino médio. In: (Org.). Políticas educativas e dinâmicas curriculares no Brasil e em Portugal. Petrópolis, RJ: Faperj, 2008. p. 189-213.

MELO, Savana D. G.; DUARTE, Adriana. Políticas para o ensino médio no Brasil: perspectivas para a universalização. Caderno Cedes, v. 31, n. 84, p. 231-251, maio-ago. 2011.

NOVAES, Regina. Políticas de juventude no Brasil: continuidades e rupturas. In:

Juventudes e contemporaneidade. Brasília: Unesco, MEC, Anped, 2007. 284 p. (Coleção Educação para Todos; 16).

ORGANIZAÇÃO DAS NAÇÕES UNIDAS PARA A EDUCAÇÃO, A CIÊNCIA E A CULTURA (Unesco). Protótipos curriculares de ensino médio e ensino médio integrado: resumo executivo. Brasília: Unesco, 2011.

ORLANDI, Eni. Análise de discurso: Michel Pêcheux. Campinas: Pontes, 2011.

SANTA CATARINA. Secretaria de Estado da Educação. Novas perspectivas para o cotidiano escolar: ensino médio integral. Florianópolis, 2011.

SARLO, Beatriz. Cenas da vida pós-moderna. Intelectuais, Artes e Videocultura na Argentina. Rio de Janeiro: UFRJ, 1997. 
SAVAGE, Jon. A criação da juventude. Como o conceito de teenage revolucionou o século XX. Rio de Janeiro: Rocco, 2009.

SILVA, Tomaz Tadeu. Documentos de identidade: uma introdução às teorias do currículo. Belo Horizonte: Autêntica, 2005.

SOARES, Rosangela. Adolescência: monstruosidade cultural? Educação \& Realidade, Porto Alegre, v. 25, n. 2, p. 151-159, jul./dez. 2000.

UNESCO. Protótipos curriculares de ensino médio e ensino médio integrado: resumo executivo. Série Debates ED, n 1 , maio 2011.

VALLE, Ione R.; DALLABRIDA, Norberto. Ensino médio em Santa Catarina: histórias, políticas, tendências. Florianópolis: Cidade Futura, 2006.

WITTGENSTEIN, Ludwig. Investigações filosóficas. Tradução de José Carlos Bruni. São Paulo: Nova Cultural, 1999. (Coleção Os Pensadores).

Data de submissão: 24/02/2016

Data de aceite: 05/03/2017 